\title{
An Improved Prediction Model Based on Grey Clustering Analysis Method and its Application in Power Load Forecasting
}

\author{
Wang Ya \\ Institute of Information Engineering, Xuchang University \\ Xuchang, Henan Province, China \\ wangya_xcc@126.com
}

\begin{abstract}
Current grey clustering analysis methods have some defects. So, this paper proposes a prediction model based on improved grey clustering analysis. Firstly, it constructs the grey classical domain and the grey sector domain based on prediction subjects and data and according to relevant theory about grey clustering analysis. Secondly, it categorizes samples according to features of prediction subjects and confirms the analysis categories corresponding to the classical domain. Thirdly, based on the grey system theory, it constructs the grey correlation coefficient model and grey correlation degree model so as to obtain the weighed grey correlation degree. Thus, prediction subjects can be divided into proper category. Finally, power load forecasting in the power industry is taken as a case to prove that the model is reliable and has efficacy.
\end{abstract}

Keywords: grey clustering analysis; grey prediction; classical domain; correlation degree; power load forecasting; model

\section{Introduction}

Today's world is advancing towards a higher level of social productivity and a rapid development of science and technology. Prediction analysis, which depends on the analysis result to reduce uncertainties about the future, has received widely attention and been applied to many fields, in particular the engineering industry [1-3]. It gives instructions on decision and planning so as to avoid blindness. The prediction analysis on complex systems is defined as to use quantitative and qualitative methods to estimate, measure and analyze design features (either internal or external) or development state of the complex system according to data available [4-5]. At present, common methods of prediction analysis include qualitative analysis, mathematical models such as time-series model, and regression model and simulation methods such as dynamic demand system. These methods are tailored to different situations and have yielded fruitful results [6-9]. A new theory, the grey system theory, is worthy of noticing. It was first put forward by Professor Deng Julong. Grey system an emerging subject aimed at solving problems with many uncertainties based on mathematical theories. It is well applied to address samples with "clear extension but blur connotation" or situations where there are only a small scale of samples and a lack of enough information [10-15]. The prediction of a complex system usually involves grey information. Therefore, this paper proposes an improved prediction model based on grey system theory and proves the efficacy of the model through a case study.

\section{Grey Sequence and Grey Correlation Coefficient}

According to the grey system theory, sub-systems at different levels are subject to grey correlation analysis. The development state, correlation of indicators and dynamic change 
of the system are measured in a quantitative way. There are two key concepts, namely grey sequence and grey correlation coefficient.

\subsection{Grey Sequence}

The change of the state of the complex system has a time-series feature. ${ }^{n}$ Correlation factors of the complex system consist of the sequence, named the comparative sequence ${ }^{V_{i}}$. Then $m$ comparative sequences corresponding to $m$ time-series state are:

$$
\begin{aligned}
& V_{1}=\left\{v_{1}(1), v_{1}(2), \cdots, v_{1}(n)\right\} \\
& V_{2}=\left\{v_{2}(1), v_{2}(2), \cdots, v_{2}(n)\right\} \\
& \cdots \cdots \\
& V_{m}=\left\{v_{m}(1), v_{m}(2), \cdots, v_{m}(n)\right\}
\end{aligned}
$$

In particular, the sequence that can reflect the behavior and state of the complex system is named reference sequence ${ }^{V_{0}}$. There is:

$$
V_{0}=\left\{v_{0}(1), v_{0}(2), \cdots, v_{0}(n)\right\}
$$

\subsection{Grey Correlation Coefficient}

To show the correlation of the development state under different time-series, grey correlation coefficient $\xi_{i}$ is used to describe how the correlation changes with the time and grey correlation degree ${ }^{r_{i}}$ is used to describe how the correlation changes with the subjects.

Grey correlation coefficient $\xi_{i j}$ can represent the correlation between the comparative sequence $V_{i}$ and the reference sequence ${ }^{V_{0}}$ under different influence factors. There is:

$$
\xi_{i j}=\frac{\min _{i} \min _{j}\left|\Delta\left(v_{i}(j)-v_{0}(j)\right)\right|+\beta \max _{i} \max _{j}\left|\Delta\left(v_{i}(j)-v_{0}(j)\right)\right|}{\left|\Delta\left(v_{i}(j)-v_{0}(j)\right)\right|+\beta \max _{i} \max _{j}\left|\Delta\left(v_{i}(j)-v_{0}(j)\right)\right|}
$$

Where ${ }^{\beta}$ refers to the resolution coefficient $\beta \in[0,1]$, usually $\beta=0.5$. $\Delta\left(v_{i}(j)-v_{0}(j)\right)$ Refers to the gap of two values.

Grey correlation degree ${ }^{r_{i}}$ refers to the closeness of two curves of the comparative sequence $V_{i}$ and the reference sequence ${ }^{V_{0}}$. There is: $r_{i}=\frac{1}{n} \sum_{j=1}^{n} \xi_{i j}$

\section{An Improved Prediction Model Based on Grey Clustering Analysis}

\subsection{Grey Classical Domain and Grey Sector Domain}

In the grey clustering analysis, the primary thing is to categorize different state sets $P$ through clustering analysis. Feature indicators in each set have a certain range of value of 
quantity. Based on that, construct the grey classical domain and the grey sector domain. Suppose the classical domain ${ }^{V_{j}^{i}}$ of the state set ${ }^{P_{i}}$ about feature ${ }^{j}$ is:

$$
V_{j}^{i}=\left\langle v_{j}^{i}(a), v_{j}^{i}(b)\right\rangle, v_{j}^{i}(a) \leq v_{j}^{i}(b)
$$

Thus, the sector domain ${ }^{o}{ }_{j}^{o}$ of the state set $P_{i}$ about indicator ${ }^{j}$ is:

$$
V_{j}^{o}=\left\langle v_{j}^{o}(a), v_{j}^{o}(b)\right\rangle=\left\langle\min \left(v_{j}^{i}(a)\right), \max \left(v_{j}^{i}(b)\right)\right\rangle
$$

\subsection{The Weight of Prediction Feature}

There are many influence factors for the complex system. The importance of prediction features varies from one another. So it is necessary to allocate weight for these features. This paper adopts a comprehensive evaluation method to allocate weight. $X$ Experts are invited to score on the importance of prediction features by a 1-9 scale. Based on the score, we can get the initial judgment matrix $\boldsymbol{B}$.

$$
\boldsymbol{B}=\left[\begin{array}{cccc}
b_{11} & b_{12} & \cdots & b_{1 n} \\
b_{21} & b_{22} & \cdots & b_{2 n} \\
\vdots & \vdots & \vdots & \vdots \\
b_{X 1} & b_{X 2} & \cdots & b_{X n}
\end{array}\right]
$$

So the weight ${ }^{w_{j}}$ of predicator feature ${ }^{j}$ is:

$w_{j}=\sum_{i=1}^{x} b_{i j} / \sum_{j=1}^{n} \sum_{i=1}^{x} b_{i j}$

\subsection{Processing Prediction Features}

Prediction features usually have different scales. To facilitate the prediction analysis, we need to nondimensionalize the classical domain of the prediction feature in order to unify the value scales.

For classical domain $U_{j}^{i}=\left\langle u_{j}^{i}(a), u_{j}^{i}(b)\right\rangle$ of prediction features of effective type, the unified value of quantity ${ }_{j}^{i}=\left\langle v_{j}^{i}(a), v_{j}^{i}(b)\right\rangle$ is:

$$
V_{j}^{i}=\left\langle v_{j}^{i}(a), v_{j}^{i}(b)\right\rangle=\left\langle\frac{u_{j}^{i}(a)-\min _{1 \leq i \leq m}\left(u_{j}^{i}(a)\right)}{\max _{1 \leq i \leq m}\left(u_{j}^{i}(b)\right)-\min _{1 \leq i \leq m}\left(u_{j}^{i}(a)\right)}, \frac{u_{j}^{i}(b)-\min _{1 \leq i \leq m}\left(u_{j}^{i}(a)\right)}{\underset{1 \leq i \leq m}{\max }\left(u_{j}^{i}(b)\right)-\min _{1 \leq i \leq m}\left(u_{j}^{i}(a)\right)}\right\rangle
$$

For classical domain $U_{j}^{i}=\left\langle u_{j}^{i}(a), u_{j}^{i}(b)\right\rangle$ of prediction features of effective type, the unified value of quantity $V_{j}^{i}=\left\langle v_{j}^{i}(a), v_{j}^{i}(b)\right\rangle$ is:

$$
V_{j}^{i}=\left\langle v_{j}^{i}(a), v_{j}^{i}(b)\right\rangle=\left\langle\frac{\max _{1 \leq i \leq m}\left(u_{j}^{i}(b)\right)-u_{j}^{i}(a)}{\max _{1 \leq i \leq m}\left(u_{j}^{i}(b)\right)-\min _{1 \leq i \leq m}\left(u_{j}^{i}(a)\right)}, \frac{\max _{1 \leq i \leq m}\left(u_{j}^{i}(b)\right)-u_{j}^{i}(b)}{\max _{1 \leq i \leq m}\left(u_{j}^{i}(b)\right)-\min _{1 \leq i \leq m}\left(u_{j}^{i}(a)\right)}\right\rangle
$$


After standardization, all values of quantity of classical domains fall between $0-1$. In other word, there is $0 \leq v_{j}^{i}(a) \leq v_{j}^{i}(b) \leq 1$, which is conductive to the grey clustering analysis of prediction feature of the complex system.

\subsection{Grey Correlation Coefficient and Grey Correlation Degree}

Suppose the sample sequence of the system to be tested is $V_{d}$ :

$$
V_{d}=\left\{v_{d}(1), v_{d}(2), \cdots, v_{d}(n)\right\}
$$

According to abovementioned analysis, standardize the sample sequence $V_{d}$ and obtain the grey correlation coefficients $\xi_{i j}^{d}$ between sequence about prediction feature ${ }^{j}$ and different classical domains $V_{j}^{i}=\left\langle v_{j}^{i}(a), v_{j}^{i}(b)\right\rangle$ :

$$
\xi_{i j}^{d}=\frac{\min _{i} \min _{j}\left\langle v_{d}(j), V_{j}^{i}\right\rangle+\beta \underset{i}{\max \max _{j} d\left\langle v_{d}(j), V_{j}^{i}\right\rangle}}{d\left\langle v_{d}(j), V_{j}^{i}\right\rangle+\beta \max _{i} \max _{j} d\left\langle v_{d}(j), V_{j}^{i}\right\rangle}
$$

Where $d\left\langle v_{d}(j), V_{j}^{i}\right\rangle$ refers to the distance between prediction feature ${ }^{j}$ and different classical domains $V_{j}^{i}=\left\langle v_{j}^{i}(a), v_{j}^{i}(b)\right\rangle$ :

$$
d\left\langle v_{d}(j), V_{j}^{i}\right\rangle=\frac{\left|v_{d}(j)-v_{j}^{i}(a)\right|+\left|v_{d}(j)-v_{j}^{i}(b)\right|}{2}
$$

After the grey correlation coefficients are obtained, we need to analyze the category of the system, namely the grey correlation degree ${ }^{r_{i}^{d}}$ between sequence $V_{d}$ about prediction feature ${ }^{j}$ and different classical domains $V_{j}^{i}=\left\langle v_{j}^{i}(a), v_{j}^{i}(b)\right\rangle$ :

$$
r_{i}^{d}=\sum_{j=1}^{n}\left(w_{j} * \xi_{i j}^{d}\right)
$$

Obtain the grey correlation degree ${ }^{r_{i}^{d}}$ between the system and the category sets and select the maximum grey correlation degree ${ }^{r_{s}^{d}}$ following the optimum principle. Its corresponding category is the state set in which the system falls:

$$
r_{s}^{d}=\max \left(r_{1}^{d}, r_{2}^{d}, \cdots, r_{m}^{d}\right)
$$

\subsection{The Model and the Algorithm}

According to abovementioned analysis, we first construct the grey classical domain and the grey sector domain by comparing prediction features on the basis of grey clustering analysis and we can get the grey correlation coefficient and grey correlation degree between the system and different categories. Then, according to the comprehensive grey correlation degree, we can figure out which state set the system belongs to and finally are able to get the prediction result.

To be more specific, the algorithm of the prediction model based on the improved grey clustering analysis is described as followings: 
Step 1 Obtain time-series sequences on the basis of influence factors of the system

Step 2 Categorize the state according to prediction features of the system and confirm the state sets or the category set.

Step 3 Construct the grey classical domain and the grey sector domain of different category sets.

Step 4 Standardize prediction features of different types and scales and allocate weight to them.

Step 5 Obtain influence factors of the system and the grey correlation coefficients between influence factors and different category sets.

Step 6 Obtain the grey correlation degrees between the system and the category sets.

Step 7 Confirm to which category the system belongs based on grey correlation degree and get the prediction result of grey clustering analysis.

Step 8 Judge whether the result reaches the prediction accuracy. If not, detail the category and repeat Step 2-7.

\section{Case Study of Power Loading Forecast}

Power loading is crucial for regional economic development. It holds significance to predict power loading in different phase to ensure sufficient power supply as enough supply provides support for a rapid, reliable and stable development of regional economy. However, power loading is limited to many factors. An accurate prediction cannot be realized unless these factors are categorized. This paper proposes an improved prediction model for the complex system in order to realize effective power loading prediction. Through surveys and inspections, it is known that there is a relation between the power loading and the development state of the industry. Sequences of the latest 10 years are obtained after statistics analysis, as shown in Table 1.

Table 1. Power Loading and the Development of the Industry

\begin{tabular}{|c|c|c|c|c|}
\hline \multirow{2}{*}{ Year } & \multicolumn{3}{|c|}{$\begin{array}{l}\text { Influence factors-industrial value } \\
\text { (100 million yuan) }\end{array}$} & \multirow{2}{*}{$\begin{array}{c}\text { Power } \\
\text { loading / } \\
100 \text { million } \\
k W h\end{array}$} \\
\hline & $\begin{array}{l}\text { Primary } \\
\text { industry }\end{array}$ & $\begin{array}{l}\text { Secondary } \\
\text { industry }\end{array}$ & $\begin{array}{l}\text { Tertiary } \\
\text { industry }\end{array}$ & \\
\hline 2005 & 67.278 & 86.452 & 32.439 & 31.211 \\
\hline 2006 & 80.767 & 100.382 & 41.926 & 38.635 \\
\hline 2007 & 90.331 & 135.624 & 50.356 & 44.662 \\
\hline 2008 & 95.467 & 158.687 & 58.735 & 47.934 \\
\hline 2009 & 108.623 & 170.981 & 66.546 & 55.157 \\
\hline 2010 & 121.938 & 195.234 & 74.325 & 67.433 \\
\hline 2011 & 131.346 & 248.805 & 89.987 & 79.127 \\
\hline 2012 & 148.639 & 298.556 & 123.768 & 99.223 \\
\hline 2013 & 198.639 & 375.466 & 165.620 & 127.316 \\
\hline
\end{tabular}

To better construct the grey classical domain and the grey sector domain, we use feature growth rate to describe characteristic quantity, as shown in Table 2.

\section{Table 2. Power Loading and the Growth Rate of Development Value of the} Industry

\begin{tabular}{|c|c|c|c|c|}
\hline \multirow{2}{*}{ Year } & \multicolumn{3}{|c|}{$\begin{array}{l}\text { Influence factors-industrial value(100 } \\
\text { million yuan) }\end{array}$} & \multirow{2}{*}{$\begin{array}{c}\text { Power } \\
\text { loading / } \\
100 \text { million } \\
k W h \\
\end{array}$} \\
\hline & $\begin{array}{l}\text { Primary } \\
\text { industry }\end{array}$ & $\begin{array}{c}\text { Secondary } \\
\text { industry }\end{array}$ & $\begin{array}{l}\text { Tertiary } \\
\text { industry }\end{array}$ & \\
\hline 2006 & 0.2004 & 0.1611 & 0.2925 & 0.2379 \\
\hline
\end{tabular}




\begin{tabular}{|l|l|l|l|l|}
\hline 2007 & 0.1184 & 0.3511 & 0.2011 & 0.1560 \\
\hline 2008 & 0.0569 & 0.1701 & 0.1664 & 0.0733 \\
\hline 2009 & 0.1378 & 0.0775 & 0.1330 & 0.1507 \\
\hline 2010 & 0.1226 & 0.1418 & 0.1169 & 0.2226 \\
\hline 2011 & 0.0771 & 0.2744 & 0.2107 & 0.1734 \\
\hline 2012 & 0.1317 & 0.1999 & 0.3754 & 0.2540 \\
\hline 2013 & 0.3364 & 0.2576 & 0.3381 & 0.2831 \\
\hline
\end{tabular}

From Table 2, we can see the growth rate of power loading ranges between 0.0700.300 . If measured by such a growth rate $\eta($ pow $)$, there are four prediction categories of power loading, namely:

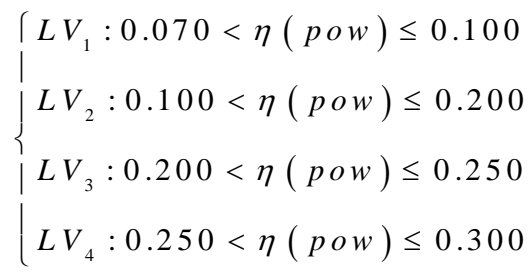

Primary industry, secondary industry and tertiary industry serve as three prediction features. We can get the average prediction feature under each category. Construct the grey classical degree of each of the four categories, as is shown in Table 3.

Table 3. Grey Relational Coefficient of Indicators of Hardware Features

\begin{tabular}{|c|c|c|c|c|c|c|}
\hline \multirow{2}{*}{ Category } & \multicolumn{2}{|c|}{ Primary industry } & \multicolumn{2}{c|}{ Secondary industry } & \multicolumn{2}{c|}{ Tertiary industry } \\
\cline { 2 - 7 } & Average & $\begin{array}{c}\text { Classical } \\
\text { domain }\end{array}$ & Average & & Average & $\begin{array}{c}\text { Classical } \\
\text { domain }\end{array}$ \\
\hline$L V_{1}$ & 0.0569 & $\begin{array}{c}0.027- \\
0.087\end{array}$ & 0.1701 & $\begin{array}{c}0.140- \\
0.200\end{array}$ & 0.1664 & $0.136-0.196$ \\
\hline$L V_{2}$ & 0.1111 & $\begin{array}{c}0.081- \\
0.141\end{array}$ & 0.2343 & $\begin{array}{c}0.204- \\
0.264\end{array}$ & 0.1816 & $0.152-0.212$ \\
\hline$L V_{3}$ & 0.1615 & $\begin{array}{c}0.132- \\
0.192\end{array}$ & 0.1515 & $\begin{array}{c}0.122- \\
0.182\end{array}$ & 0.2047 & $0.175-0.237$ \\
\hline$L V_{4}$ & 0.1317 & $\begin{array}{c}0.101- \\
0.162\end{array}$ & 0.1999 & $\begin{array}{c}0.170- \\
0.230\end{array}$ & 0.3754 & $0.345-0.405$ \\
\hline
\end{tabular}

Classical domains of the growth rate of the three industries under different categories are taken as the comparative sequence. The growth rate of the three industries is taken as the reference sequence. We can obtain the grey correlation coefficient of prediction features, as shown in Table 4.

Table 4. Grey Correlation Coefficient of the System to be Tested

\begin{tabular}{|c|c|c|c|}
\hline \multirow{2}{*}{ Category } & \multicolumn{3}{|c|}{ Grey correlation coefficient } \\
\cline { 2 - 4 } & $\begin{array}{c}\text { Primary } \\
\text { industry }\end{array}$ & $\begin{array}{c}\text { Primary } \\
\text { industry }\end{array}$ \\
\hline$L V_{1}$ & 0.389 & 0.717 & 0.524 \\
\hline$L V_{2}$ & 0.447 & 1.000 & 0.551 \\
\hline$L V_{3}$ & 0.518 & 0.663 & 0.597 \\
\hline$L V_{4}$ & 0.473 & 0.826 & 0.921 \\
\hline
\end{tabular}

With the weight of hardware features and software features taken into account, we can get the comprehensive weighed grey relational degree of each indicator, 
namely, $\sigma_{1}=0.786, \sigma_{2}=504, \sigma_{3}=503$. By comparing the three, we can judge that object I is the optimal one and conductive to later research.

Table 5. Grey Correlation Coefficient of the System to be Tested

\begin{tabular}{|c|c|c|c|}
\hline Category & $\begin{array}{c}\text { Grey correlation } \\
\text { degree }\end{array}$ & Prediction & Weight \\
\hline$L V_{1}$ & 0.554 & $\begin{array}{c}\text { Primary } \\
\text { industry }\end{array}$ & 0.35 \\
\hline$L V_{2}$ & 0.694 & $\begin{array}{c}\text { Secondary } \\
\text { industry }\end{array}$ & 0.40 \\
\hline$L V_{3}$ & 0.596 & $\begin{array}{c}\text { Tertiary } \\
\text { industry }\end{array}$ & 0.25 \\
\hline$L V_{4}$ & 0.726 & \multicolumn{2}{c}{} \\
\hline
\end{tabular}

From Table 5, we can see the system belongs to category ${ }^{L V_{4}}$, with the range of growth rate at $0.250<\eta($ pow $) \leq 0.300$. The power loading falls into $\langle 124.028,128.990\rangle$. The actual power loading value is 127.316 , as shown in Table 1. Its growth rate is 0.2831, as shown in Table 2. As $127.316 \in\langle 124.028,128.990\rangle$ and $0.2831 \in\langle 0.250,0.300\rangle$, which indicates that the actual value is in line with the prediction. Thus, the efficacy of the model gets proved.

\section{Conclusion}

This paper studies the prediction about complicated systems and proposes an improved prediction model based on grey clustering analysis. It tests the model with a case of power loading prediction and proves that the model can fulfill the purpose. In this model, grey classical domain and grey sector domain of prediction features are constructed according to grey data sequence. The grey correlation coefficient and grey correlation degree between prediction features and different categories of classical domain are computed and the weighed grey correlation degree is obtained. Thus, the prediction of grey clustering analysis is available. The model has clear physical definitions. It is accurate and reliable in calculation, and easy to achieve on the computer. This model is able to provide support for the predication of intelligent and complicated systems.

\section{Acknowledgments}

This paper is supported by Key State Project of the Research in Science Technology of the Education Department of Henan Province (Project Name: Research in Mechanism of Syncretism and Self-control of Heterogeneous Internet of Things. Project Number: 14A510018).

\section{References}

[1] L. Xiaobai, C. Xiuling and L. Rongling, "Forecasting method for aeroengine performance parameters", Journal of Beijing University of Aeronautics and Astronautics, vol.34, no. 3, (2008), pp.253-256.

[2] Y. Xin and F. Hua, "Prediction of coal and gas outburst based on data fusion and case-based reasoning", Journal of Southeast University(Natural Science Edition), vol.41, (2011), pp.59-63.

[3] L. Fang, "Application of Grey Model and Neural Network in Grain Production Prediction", Computer Simulation, vol.29, no.4, (2012), pp.225-228+267. 
[4] L. Nihuan, H. Zhihong, M. Yingying and L. Wangyun, "Review of the short-term load forecasting methods of electric power system", Power System Protection and Control, vol.39, no.1, (2011), pp.147152.

[5] S. Qiang and Y. Jiguang, "Review on fault prognostic methods based on uncertainty", Control and Decision, vol.5, (2014), pp.769-778.

[8] W. Li, "Water bloom prediction and factor analysis based on multidimensional time series analysis", CIESC Jorunal, vol.64, no.12, (2013), pp.4649-4655.

[10] G. Wei, “An Improved GM(1,1)Forecast Model Based on the Markov Theory”, Computer Engineering and Science, vol.33, no.2, (2011), pp.159-163.

[11] T.-c. Wang, A.-j. Yang and S.-s. Zhong, "Multi-Attribute Extension Fuzzy Optimized Decision-Making Model of Scheme Design", Tehnički vjesnik/Technical Gazette, vol.21, no.2, (2014), pp.239-247.

[12] T.-F. Chuang and Y.-H. Chang, "Comparison of physical characteristics between Rana latouchtii and Rana adenopleura using grey system theory and Artificial Neural Network", Ecological Engineering, vol.68, no.7, (2014), pp.223-232.

[13] K.-C. Wang, "A hybrid Kansei engineering design expert system based on grey system theory and support vector regression", Expert Systems with Applications, vol.38, no.7, (2011), pp.8738-8750.

[14] J. J. Guo, J. Y. Wu and R. Z. Wang, "A new approach to energy consumption prediction of domestic heat pump water heater based on grey system theory", Energy and Buildings, vol.43, no.6, (2011), pp.1273-1279.

[15] S. H. Hashemi, A. Karimi and M. Tavana, "An integrated green supplier selection approach with analytic network process and improved Grey relational analysis", International Journal of Production Economics, vol.159, no., pp.178-191. 